\title{
Open-Label, Phase I, Pharmacokinetic Studies in Healthy Chinese Subjects to Evaluate the Bioequivalence and Food Effect of a Novel Formulation of Abiraterone Acetate Tablets
}

\author{
Zeying Feng ${ }^{1,2, *}$ \\ Yaxin Liu ${ }^{1,2, *}$ \\ Yun Kuang ${ }^{2}$ \\ Shuang Yang ${ }^{2}$ \\ Jinlei $\mathrm{Li}^{2}$ \\ Ling $\mathrm{Ye}^{2}$ \\ Jie Huang ${ }^{2}$ \\ Qi Pei (D) ${ }^{3}$ \\ Yuanyuan Huang ${ }^{1,4}$ \\ Guoping Yang $\mathbb{D}^{1-3}$
}

'XiangYa School of Pharmaceutical Sciences, Central South University, Changsha, Hunan, 4I00 I3, People's Republic of China; ${ }^{2}$ Center of Clinical Pharmacology, The Third Xiangya Hospital, Central South University, Changsha, Hunan, 4 I00I3, People's Republic of China; ${ }^{3}$ Department of Pharmacy, The Third Xiangya Hospital, Central South University, Changsha, Hunan, 4I0013, People's Republic of China; ${ }^{4}$ Clinical Research and Develpment Division II, Jiangsu Hengrui Medicine Co., Ltd., Shanghai, 201200, People's Republic of China

*These authors contributed equally to this work

Correspondence: Yuanyuan Huang Clinical Research and Develpment Division II, Jiangsu Hengrui Medicine Co. Ltd., I 288 Haike Road, Pudong District,

Shanghai, 20I200, People's Republic of

China

Email yuanyuan.huang@hengrui.com

Guoping Yang

The Third Xiangya Hospital, Central South University, Yinpenling Street, Yuelu District, Changsha, Hunan, 4I00I3,

People's Republic of China

Tel $+86731-89918665$

Fax $+86731-88618326$

Email ygp9880@।26.com
Purpose: Abiraterone acetate tablets $(\mathrm{I})(\mathrm{N}-\mathrm{AbA})$ is a novel tablet co-formulated with the absorption enhancer sodium N-(8-[2-hydroxybenzoyl] amino) caprylate (SNAC). This study aimed to compare the pharmacokinetics, bioequivalence, safety, and food effects of $\mathrm{N}-\mathrm{AbA}$ with the reference ZYTIGA ${ }^{\circledR}$ (R-AbA) in healthy Chinese male subjects.

Patients and Methods: This study was conducted in three parts. Part I was an open, doseescalation trial conducted in 16 Chinese healthy males; Part II was a randomized, open-label, $2 \times 4$ crossover, single-dose bioequivalence trial conducted in 36 subjects; Part III was a randomized, $3 \times$ 3 crossover trial conducted on 24 volunteers to investigate the effect of food on the pharmacokinetics of N-AbA.

Results: The exposure $\left(\mathrm{AUC}_{0-\infty}\right)$ and maximum concentration $\left(\mathrm{C}_{\max }\right)$ of abiraterone and excipient SNAC were linear in the range of 75-450 $\mathrm{mg}$ dose. The bioavailability of $\mathrm{N}-\mathrm{AbA}$ $300 \mathrm{mg}$ was equivalent to that of R-AbA $1000 \mathrm{mg}$. The drug exposure of prednisone and prednisolone was not affected by SNAC co-administration. The $\mathrm{C}_{\max }$ of orally administered abiraterone as $\mathrm{R}-\mathrm{AbA}$ in a modified fed state was 5.9 times and $\mathrm{AUC}_{0-\infty}$ was 4.3 times, respectively, higher than those in of orally administered abiraterone as N-AbA in a high-fat diet. The $\mathrm{C}_{\max }$ and $\mathrm{AUC}_{0-\infty}$ of orally administered abiraterone as $\mathrm{N}$-AbA on a high-fat diet were 2.2 times and 2 times, respectively, higher than those on a fasting state. All adverse events reported in the three parts of the study were grade 1 or 2 , and no serious adverse events were reported.

Conclusion: These three Phase I trials showed that N-AbA and excipient SNAC had excellent linear pharmacokinetic characteristics. A single dose of N-AbA $300 \mathrm{mg}$ was bioequivalent to R-AbA $1000 \mathrm{mg}$ in healthy subjects under fasting conditions. Meanwhile, SNAC had no effect on the pharmacokinetics of prednisone and prednisolone. The effect of food on N-AbA was significantly lower than that on R-AbA.

Keywords: food effect, pharmacokinetics, abiraterone acetate, bioequivalence

\section{Introduction}

Prostate cancer is one of the most common cancers among men and is the second leading cause of cancer-related death in men in the United States. ${ }^{1}$ In Asians too, the age-adjusted incidence of prostate cancer has increased gradually over time. Androgen deprivation therapy is considered the primary treatment option for metastatic prostate cancer. $^{2}$ Abiraterone is a potent and selective irreversible inhibitor of the enzyme 
CYP17A1, which is required for androgen biosynthesis. It slows the progression of prostate cancer by reducing the production of androgens in the testes, adrenal glands, and prostate tumor tissue. ${ }^{3,4}$ Abiraterone acetate, a prodrug of abiraterone and marketed under the original brand name $\mathrm{R}-\mathrm{AbA}$, is approved as a medication co-administered with prednisone for the treatment of metastatic castration-resistant prostate cancer (mCRPC) and metastatic high-risk castration-sensitive prostate cancer. ${ }^{5}$

Abiraterone acetate is a Biopharmaceutics Classification System class IV compound, with an extremely low oral bioavailability when administered in the fasted state. ${ }^{6}$ However, the administration of abiraterone acetate with highfat food results in up to a 10 -fold increased area under the concentration-time curve (AUC) and up to a 17-fold increase in the maximum plasma concentration $\left(\mathrm{C}_{\max }\right)$ of abiraterone. ${ }^{7}$ Because of the low oral bioavailability and significant food effect of abiraterone acetate, its administration carries a risk of toxicity and inaccurate dosing. ${ }^{8}$ The specification for ZYTIGA ${ }^{\circledR}$ is that abiraterone acetate should be taken on an empty stomach, at least $1 \mathrm{~h}$ before or at least 2 $\mathrm{h}$ after a meal. Its large typical daily dose (1000 mg) under the fasting condition is a significant pill burden for patients.

Abiraterone acetate tablets (I)(N-AbA), developed by Jiangsu Hengrui Medicine Co., Ltd., are prepared using nanocrystalline technology in which abiraterone acetate is co-formulated with the absorption enhancer sodium N-(8-[2-hydroxybenzoyl] amino) caprylate (SNAC). Despite not being included in the FDA list of excipients, SNAC has been widely used to enhance the oral absorption of different types of drugs. The glucagon-like peptide1 receptor agonist semaglutide co-formulated with SNAC exhibited improved drug absorption. ${ }^{9}$ This new coformulation has been approved by the FDA. ${ }^{10}$ The ability of SNAC to improve drug absorption has been demonstrated in many studies. ${ }^{11,12}$

$\mathrm{N}-\mathrm{AbA}$ was developed to promote the gastrointestinal absorption, low oral bioavailability, high pharmacokinetic variability, and food effects of abiraterone. Here, we conducted this study aimed at comparing the pharmacokinetic characteristics, safety, and food effects of $\mathrm{N}-\mathrm{AbA}$ and $\mathrm{R}-\mathrm{AbA}$.

\section{Materials and Methods}

\section{Ethics Statement}

This series of clinical trials is registered with the Chinese Clinical Trial Registry (http://www.chictr.org.cn;
ChiCTR2000032273, ChiCTR1900025101，ChiCTR1900 025027; date of registration: April 13, 2020; August 11, 2019; April 8, 2019) and has been approved by the Institutional Review Board of The Third Xiangya Hospital of Central South University (2019070, 2019091, 2019195). The study execution dates for these trials were April 8, 2020 to May 2, 2020; July 15, 2020 to August 1, 2020; and August 29, 2020 to September 22, 2020. The study was conducted in accordance with the Declaration of Helsinki (1989), the Guidelines of Good Clinical Practice, and local applicable laws and regulations. All subjects have provided written informed consent forms prior to their participation in the study.

\section{Study Design}

This study was conducted in three parts. Part I was a single-center, open, and sequential trial conducted in 16 healthy male Chinese subjects under fasting condition. All subjects were randomized to receive a single dose of $75 \mathrm{mg}, 150 \mathrm{mg}, 300 \mathrm{mg}$, and $450 \mathrm{mg} \mathrm{N}-\mathrm{AbA}$. Each of the four doses was administered with a 7-day washout period in between each dose.

Part II was a randomized, open-label, two-sequence, four-period, single-dose bioequivalence trial conducted in 36 healthy male Chinese subjects under fasting condition. All subjects were assigned with randomized numbers into two treatment sequence groups: TRTR and RTRT (where $\mathrm{T}$ refers to $300 \mathrm{mg} \mathrm{N}-\mathrm{AbA}$ with $5 \mathrm{mg}$ prednisone, and $\mathrm{R}$ refers to $\mathrm{R}-\mathrm{AbA}$ with $5 \mathrm{mg}$ prednisone). The subjects received $\mathrm{T}$ or $\mathrm{R}$ products according to the randomization schedule. The washout period was 7 days.

Part III was a randomized, open-label, three-sequence, three-period, self-crossover study conducted in 24 healthy male Chinese subjects to compare the food effects on pharmacokinetic and safety profiles between the two formulations. All subjects were randomized into one of the three cohorts: 1) subjects were administered $300 \mathrm{mg}$ $\mathrm{N}-\mathrm{AbA}$ under fasting state; 2) subjects were administered $300 \mathrm{mg} \mathrm{N}-\mathrm{AbA}$ on a high-fat diet; 3) subjects were administered $1000 \mathrm{mg}$ R-AbA on modified fed conditions. The washout period was 7 days.

For the fasting condition, the subjects were asked to fast overnight $(10 \mathrm{~h})$ prior to dosing. The high-fat diet contained about $800-1000 \mathrm{kcal}$ in total with about $50 \%$ of the calories coming from fat. The high-fat meal was provided $30 \mathrm{~min}$ before administration and finished within $30 \mathrm{~min}$. Under the modified fed condition, subjects were asked to eat a medium-fat meal ( $\sim 450 \mathrm{kcal}$ with $30 \%$ of the calories coming from fat) $2 \mathrm{~h}$ before and $1 \mathrm{~h}$ after 
administration. No water was consumed between 1 $\mathrm{h}$ before and $1 \mathrm{~h}$ after drug administration, except the $240 \mathrm{~mL}$ water to swallow the study drugs.

\section{Study Drugs}

The test drug (N-AbA) was manufactured by Chengdu Suncadia Medicine Co., Ltd. (subsidiary of Jiangsu Hengrui Medicine Co., Ltd.); specifications: $150 \mathrm{mg}$ per tablet; batch number: P20060411. The reference drug (R-AbA) was manufactured by Patheon Inc.; specifications: $250 \mathrm{mg}$ per tablet; batch number: CCTSV. The combination drug prednisone acetate tablets were manufactured by Shanghai Pharmaceuticals Sine Co., Ltd.; specifications: $5 \mathrm{mg}$ per tablet; batch number: 018190903.

\section{Pharmacokinetic Evaluation, Blood Sample Collection, and Bioanalytical Assay}

Plasma concentrations of abiraterone and SNAC were measured in all three trials in this study. In Part II, prednisone and prednisolone concentrations were also tested. Blood samples were collected prior to dosing $(0 \mathrm{~h})$ and at $0.25,0.5,0.75,1,1.25,1.5,1.75,2,2.5,3,4,5,6,8,12$, 24, 36 and 48 h post-dose. For Part II, blood samples were also collected at 3.5 and $4.5 \mathrm{~h}$ post-dose. Blood samples were centrifuged at $1300 \times \mathrm{g}$ for $10 \mathrm{~min}$ at $4^{\circ} \mathrm{C}$. The obtained plasma samples were stored in a refrigerator at $-20 \pm 5^{\circ} \mathrm{C}$ for pre-freezing, and the samples were transferred to the refrigerator at $\leq-60^{\circ} \mathrm{C}$ on the last day in each period for subsequent analyses. The time from the end of centrifugation to freezer storage was less than $1 \mathrm{~h}$.

The serum concentration of abiraterone, SNAC, prednisone, and prednisolone was detected by HPLC-MS/MS. The limit of quantification of abiraterone, SNAC, prednisone, and prednisolone was 0.100-400, 0.250-1000, $0.500-50.0$, and $2.00-200 \mathrm{ng} / \mathrm{mL}$. Of all analytical methods of four compounds, the percent co-efficient of variation of inter-assay precision was $\leq 7.4 \%$, and the assay accuracy was in the range of $-8.0 \%$ to $1.7 \%$.

\section{Safety Assessments}

Safety was evaluated by observing vital signs, physical examination, electrocardiography, laboratory examination (blood routine, blood biochemistry, blood coagulation function, urine routine, fecal routine, fecal occult blood, and blood transfusion), adverse event (AE) reporting. AEs were recorded and graded according to the National
Cancer Institute Common Terminology Criteria for Adverse Events (version 5.0). Subjects with AEs were followed up until the symptoms or the corresponding physical and clinical examinations returned to normal.

\section{Statistical Analysis}

Pharmacokinetic parameters were calculated using the noncompartmental model (NCA module) on WinNonlin 8.2 (Pharsight Corporation, Mountain View, CA, USA). Statistical analysis was performed with SAS 9.4 Statistical Package (SAS Institute Inc., Cary, NC, USA). In Part I, the confidence interval method was used to analyze the linear relationship of AUC and $\mathrm{C}_{\max }$ with the dose. The natural logarithm of AUC and $\mathrm{C}_{\max }$ was used to perform linear regression analysis with the dose. The slope of the linear regression equation and $90 \%$ confidence interval were observed. In Part II, natural log-transformed $\mathrm{AUC}_{0-\mathrm{t}}$, $\mathrm{AUC}_{0-\infty}$, and $\mathrm{C}_{\max }$ were analyzed by analysis of variance with a mixed-effects model. Treatment sequence, formulation, and period were the fixed effect variables, and participant was the random effect variable. The relative bioavailability of the test drug and reference drug was evaluated based on average bioequivalence (ABE) or reference-scaled average bioequivalence (RSABE). In Part III, the least-squares mean ratios and $90 \%$ confidence intervals of $\mathrm{C}_{\max }, \mathrm{AUC}_{0-\mathrm{t}}$, and $\mathrm{AUC}_{0-\infty}$ of abiraterone in the plasma were calculated after oral administration under different feeding conditions. The adjusted mean differences and 90\% CIs for the differences were exponentiated to provide estimates of the ratio of adjusted geometric means (test $/$ reference) and $90 \%$ CIs for the ratios.

\section{Results}

\section{Participant Demographics}

A total of 76 healthy male subjects were enrolled in this study (Part I: $n=16$; Part II: $n=36$; Part III: $n=24$ ). One subject dropped out in each of the three parts of the study due to AEs. The flowchart of the subject distribution is shown in Figure 1. The median age of the subjects was $28.25,27.81$, and 25.08 years in the three trials. The median body mass index was $21.61,22.24$, and $21.44 \mathrm{~kg} /$ $\mathrm{m}^{2}$. The participant characteristics are shown in Table 1 .

\section{Pharmacokinetics}

\section{Part I}

The plasma concentration profiles and pharmacokinetic parameters of abiraterone and SNAC are shown in 

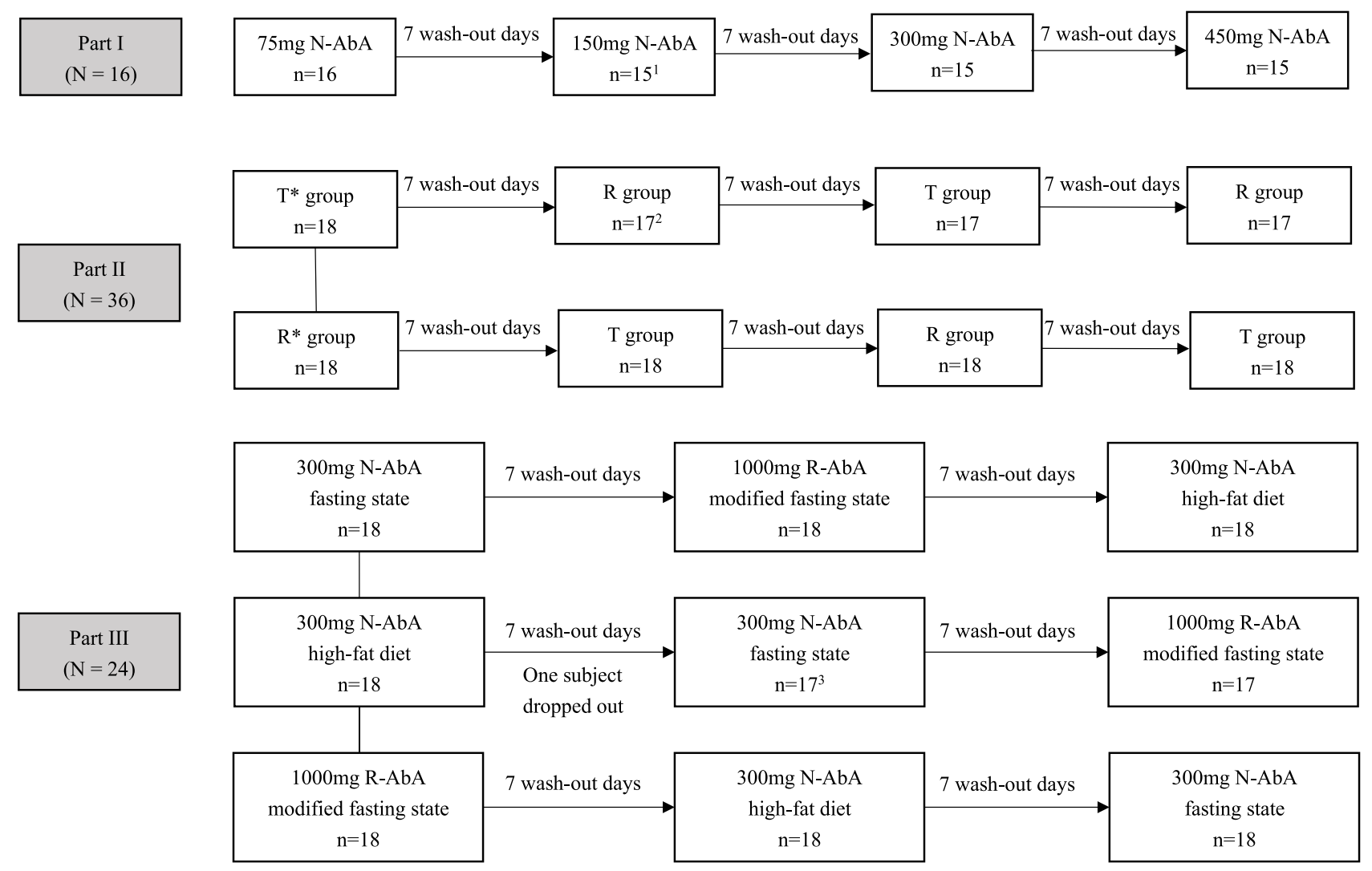

Figure I The flowchart of the subject disposition. 'one subject dropped out because of elevating the level of uric acid. ${ }^{2}$ one subject dropped out because of elevating the level of triglycerides. ${ }^{3}$ one subject dropped out because of elevating the level of blood bilirubin. *T group: 300mg N-AbA $+5 \mathrm{mg}$ prednisone; $1000 \mathrm{mg}$ R-AbA $+5 \mathrm{mg}$ prednisone.

Table 2. The median $\mathrm{T}_{\max }$ of abiraterone and SNAC was approximately $1 \mathrm{~h}$ and $0.5 \mathrm{~h}$, respectively. Following the oral administration of $75-450 \mathrm{mg} \mathrm{AbA}$, the $\mathrm{C}_{\max }$ and

Table I Demographics and Characteristics of Subjects

\begin{tabular}{|c|c|c|c|}
\hline Characteristics & $\begin{array}{l}\text { Part I } \\
(n=16)\end{array}$ & $\begin{array}{l}\text { Part II } \\
(n=36)\end{array}$ & $\begin{array}{l}\text { Part III } \\
(n=24)\end{array}$ \\
\hline \multicolumn{4}{|l|}{ Age (year) } \\
\hline Median \pm SD & $28.25 \pm 6.34$ & $27.81 \pm 6.15$ & $25.08 \pm 5.93$ \\
\hline Range & $19.00 \sim 37.00$ & $20.00 \sim 45.00$ & $18.00 \sim 38.00$ \\
\hline \multicolumn{4}{|l|}{ Gender (n\%) } \\
\hline Male & $16(100.0 \%)$ & $36(100.0 \%)$ & $24(100.0 \%)$ \\
\hline Female & $0(0.0 \%)$ & $0(0.0 \%)$ & $0(0.0 \%)$ \\
\hline \multicolumn{4}{|l|}{ Weight (kg) } \\
\hline Median \pm SD & $61.07 \pm 6.67$ & $62.76 \pm 7.11$ & $61.25 \pm 5.16$ \\
\hline Range & $50.60 \sim 75.90$ & $51.50 \sim 79.20$ & $53.70 \sim 73.10$ \\
\hline \multicolumn{4}{|l|}{ BMI $\left(\mathrm{kg} / \mathrm{m}^{2}\right)$} \\
\hline Median \pm SD & $21.61 \pm 1.49$ & $22.24 \pm 1.88$ & $21.44 \pm 1.81$ \\
\hline Range & $19.40 \sim 24.10$ & $19.30 \sim 25.70$ & $19.10 \sim 25.90$ \\
\hline \multicolumn{4}{|l|}{ Height (cm) } \\
\hline Median \pm SD & $167.91 \pm 6.45$ & $167.86 \pm 6.21$ & $169.06 \pm 4.73$ \\
\hline Range & $156.50 \sim 178.00$ & |49.5 | 78.50 & $160.00 \sim 176.50$ \\
\hline
\end{tabular}

Abbreviation: BMI, body mass index.
$\mathrm{AUC}_{0-\infty}$ of abiraterone and SNAC were proportional to the dose (Figure 2).

\section{Part II}

After the administration of $300 \mathrm{mg}$ N-AbA with $5 \mathrm{mg}$ prednisone tablet or $1000 \mathrm{mg}$ R-AbA with $5 \mathrm{mg}$ prednisone tablet, the mean plasma concentration profiles under fasting condition are shown in Figure 3. For the test group, compared to the reference group, the geometric mean ratios of $\mathrm{C}_{\max }, \mathrm{AUC}_{0-\infty}$, and $\mathrm{AUC}_{0-\mathrm{t}}$ were $106.62 \%$, $92.38 \%$, and $94.01 \%$, respectively. All 90\% confidence intervals (CIs) were within the range of $80-125 \%$. To evaluate the effect of SNAC on the pharmacokinetics of prednisone, we compared the $\mathrm{C}_{\max }, \mathrm{AUC}_{0-\infty}$, and $\mathrm{AUC}_{0-\mathrm{t}}$ of prednisone and prednisolone between the two groups and found that these pharmacokinetic parameters of prednisone and prednisolone were similar between the test and reference groups (Table 3).

Part III

The pharmacokinetic profiles of abiraterone under fasting conditions (300 mg N-AbA), high-fat diet conditions 
Table 2 PK Parameters of Abiraterone and SNAC After Dosing Abiraterone Acetate with Different Doses

\begin{tabular}{|c|c|c|c|c|}
\hline \multirow{2}{*}{$\begin{array}{l}\text { Parameters } \\
\text { Mean } \pm \text { SD (CV\%) }\end{array}$} & \multicolumn{4}{|c|}{ Abiraterone } \\
\hline & $75 \mathrm{mg}(n=16)$ & $150 \mathrm{mg}(n=15)$ & $300 \mathrm{mg}(n=15)$ & $50 \mathrm{mg}(\mathrm{n}=15)$ \\
\hline $\mathrm{C}_{\max }(\mathrm{ng} / \mathrm{mL})$ & $33.9 \pm 12.9(38.1)$ & $81.4 \pm 45.0(55.3)$ & $209 \pm 142(67.8)$ & $405 \pm 428(106)$ \\
\hline$A \cup C_{0-t}(\mathrm{ng} \cdot \mathrm{h} / \mathrm{mL})$ & $98.96 \pm 46.29(46.77)$ & $246.11 \pm 97.19$ (39.49) & $620.08 \pm 370.19(59.70)$ & $1041.37 \pm 903.24(86.74)$ \\
\hline$A \cup C_{0-\infty}(\mathrm{ng} \cdot \mathrm{h} / \mathrm{mL})$ & $|0| .27 \pm 46.6 \mid(46.02)$ & $250.27 \pm 97.95(39.14)$ & $627.60 \pm 370.44(59.02)$ & $1054.58 \pm 904.86(85.80)$ \\
\hline $\mathrm{T}_{\max } *(\mathrm{~h})$ & $1.13(0.5-2.5)$ & $1.0(0.5-1.25)$ & $1.0(0.5-2.00)$ & $1.0(0.75-3.00)$ \\
\hline $\mathrm{tl} / 2_{\mathrm{z}}(\mathrm{h})$ & $10.15 \pm 3.1(30.52)$ & $10.7 \mid \pm 2.03(\mid 8.96)$ & $10.62 \pm 1.80(16.94)$ & $10.85 \pm|.5|(\mid 3.95)$ \\
\hline Parameters & \multicolumn{4}{|c|}{ SNAC } \\
\hline Mean \pm SD (CV\%) & $75 \mathrm{mg}(\mathrm{n}=16)$ & $150 \mathrm{mg}(n=15)$ & $300 \mathrm{mg}(\mathrm{n}=15)$ & $50 \mathrm{mg}(n=15)$ \\
\hline $\mathrm{C}_{\max }(\mathrm{ng} / \mathrm{mL})$ & $407 \pm 140(34.4)$ & $977 \pm 385(39.4)$ & $1870 \pm 484(25.9)$ & $2460 \pm 963(39.2)$ \\
\hline$A \cup C_{0-t}(\mathrm{ng} \cdot \mathrm{h} / \mathrm{mL})$ & $291.34 \pm 61.44(21.09)$ & $668.36 \pm 153.26(22.93)$ & $1396.58 \pm 284.15(20.35)$ & $2121.8 \pm 491.85(23.18)$ \\
\hline$A \cup C_{0-\infty}(\mathrm{ng} \cdot \mathrm{h} / \mathrm{mL})$ & $294.82 \pm 61.4(20.83)$ & $672.15 \pm 152.2(22.64)$ & $1409.79 \pm 285.05(20.22)$ & $2131.49 \pm 490.78(23.03)$ \\
\hline $\mathrm{T}_{\max } *(\mathrm{~h})$ & $0.38(0.25-1.25)$ & $0.5(0.25-0.75)$ & $0.5(0.25-1.75)$ & $0.5(0.25-0.75)$ \\
\hline $\mathrm{tl} / 2_{\mathrm{z}}(\mathrm{h})$ & $3.53 \pm 2.54(71.79)$ & $2.94 \pm 1.39(47.26)$ & $5.35 \pm 3.92(73.26)$ & $4.88 \pm 2.37(48.47)$ \\
\hline
\end{tabular}

Abbreviations: $C_{\max }$, the highest plasma concentration of the drug; $A \cup C_{0-t}$, the area under the plasma concentration-time curve from time zero to the last quantifiable concentration time; $\mathrm{AUC}_{0-\infty}$, the area under the plasma concentration-time curve from time zero extrapolated to infinite time.

(300 mg N-AbA), and modified fed conditions (1000 mg $\mathrm{R}-\mathrm{AbA}$ ) are shown in Figure 4. The $\mathrm{C}_{\max }$ of abiraterone as orally administered R-AbA on a modified fed state was 5.89 times and $\mathrm{AUC}_{0-\infty}$ was 4.3 times, respectively, higher than that of abiraterone as orally administered $\mathrm{N}-\mathrm{AbA}$ on a high-fat diet. Under the fasting state, the $\mathrm{C}_{\max }$ of abiraterone as orally administered $\mathrm{N}-\mathrm{AbA}$ on a high-fat diet was 2.2 times and $\mathrm{AUC}_{0-\infty}$ was 2 times, respectively,
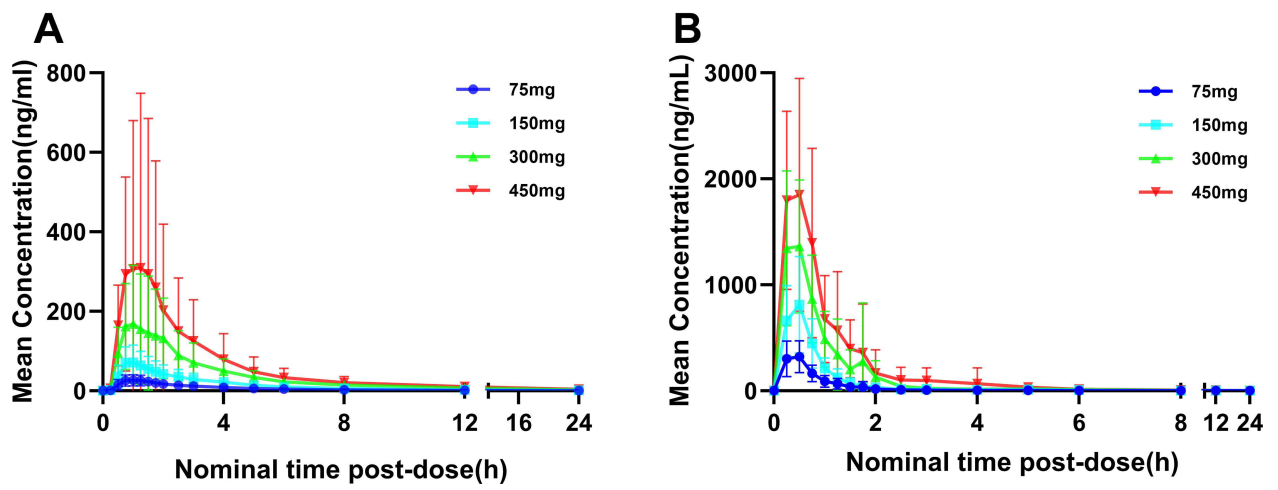

Figure 2 Linear scale of mean plasma concentration-time plot of Abiraterone (A) and SNAC (B).
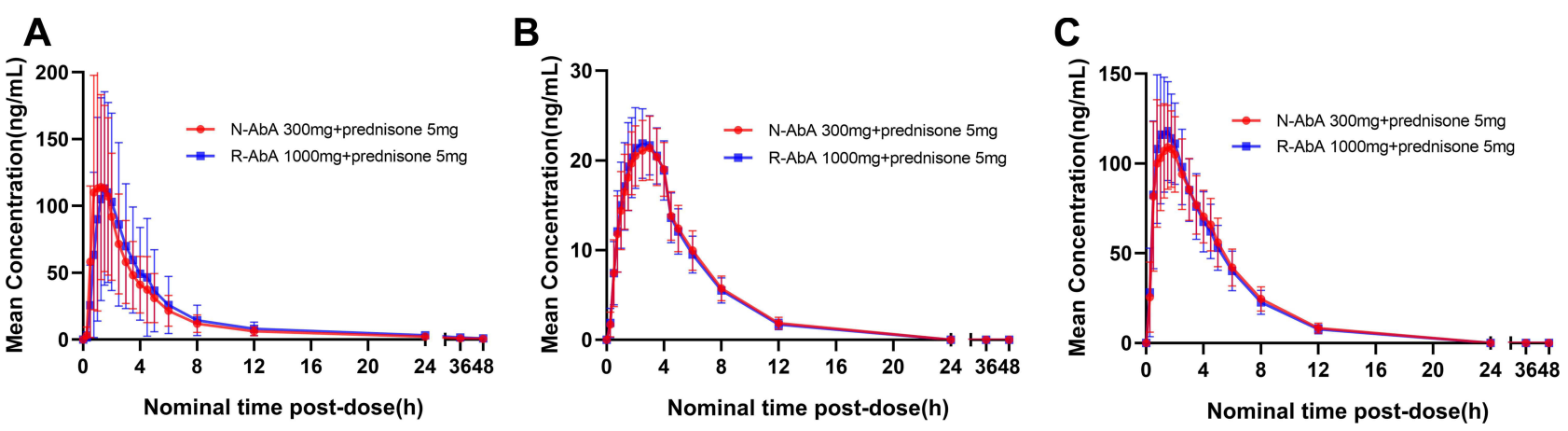

Figure 3 Mean plasma concentration-time plot of Abiraterone (A), prednisone (B) and prednisolone (C) for R and T groups. 
Table 3 Summary of Bioequivalence Analysis Under Fasting Conditions

\begin{tabular}{|c|c|c|c|c|}
\hline \multirow[t]{2}{*}{ PK Parameters } & \multicolumn{3}{|c|}{ Geometric Mean (Abiraterone) } & \multirow[t]{2}{*}{$90 \% \mathrm{Cl}$} \\
\hline & $T *(n=36)$ & $R^{*}(n=35)$ & Ratio (\%) & \\
\hline $\mathrm{C}_{\max }(\mathrm{ng} / \mathrm{mL})$ & 151.67 & 142.25 & 106.62 & $95.73 \sim 118.76$ \\
\hline$A \cup C_{0-t}\left(n g^{*} / m L\right)$ & 456.50 & 485.58 & 94.01 & $87.42 \sim 101.10$ \\
\hline $\mathrm{AUC}_{0-\infty}(\mathrm{ng} * \mathrm{~h} / \mathrm{mL})$ & 464.43 & 502.74 & 92.38 & $86.00 \sim 99.23$ \\
\hline PK Parameters & \multicolumn{3}{|c|}{ Geometric Mean (Prednisone) } & $90 \% \mathrm{Cl}$ \\
\hline & $T^{*}(n=36)$ & $R *(n=35)$ & Ratio (\%) & \\
\hline $\mathrm{C}_{\max }(\mathrm{ng} / \mathrm{mL})$ & 22.58 & 23.31 & 96.89 & $94.22 \% \sim 99.63 \%$ \\
\hline $\mathrm{AUC}_{0-\mathrm{t}}(\mathrm{ng} \cdot \mathrm{h} / \mathrm{mL})$ & 122.16 & 121.88 & 100.23 & $98.26 \% \sim 102.24 \%$ \\
\hline$A \cup C_{0-\infty}(\mathrm{ng} \cdot \mathrm{h} / \mathrm{mL})$ & 128.85 & 127.77 & 100.84 & $98.81 \% \sim 102.92 \%$ \\
\hline PK Parameters & \multicolumn{3}{|c|}{ Geometric Mean (Prednisolone) } & $90 \% \mathrm{Cl}$ \\
\hline & $\mathrm{T} *(\mathrm{n}=36)$ & $R^{*}(n=35)$ & Ratio (\%) & \\
\hline $\mathrm{C}_{\max }(\mathrm{ng} / \mathrm{mL})$ & $|25.4|$ & 141.28 & 88.77 & $86.08 \% \sim 91.54 \%$ \\
\hline $\mathrm{AUC}_{0-\mathrm{t}}(\mathrm{ng} \cdot \mathrm{h} / \mathrm{mL})$ & 581.96 & 582.63 & 99.89 & $98.29 \% \sim 101.50 \%$ \\
\hline $\mathrm{AUC}_{0-\infty}(\mathrm{ng} \cdot \mathrm{h} / \mathrm{mL})$ & 611.50 & 609.44 & 100.34 & $98.70 \% \sim 102.01 \%$ \\
\hline
\end{tabular}

Note: $*$ T: $300 \mathrm{mg} \mathrm{N}-\mathrm{AbA}+5 \mathrm{mg}$ prednisone; R: 1000mg R-ABA+5mg prednisone.

higher. For SNAC, the geometric mean ratios of $\mathrm{C}_{\max }$, $\mathrm{AUC}_{0-\mathrm{t}}$, and $\mathrm{AUC}_{0-\infty}$ were $71.64 \%, 126.17 \%$, and $125.92 \%$, respectively, when comparing the high-fat diet condition (300 mg N-AbA) with fasting condition (300 mg $\mathrm{N}-\mathrm{AbA}$ ). The details are shown in Table 4.

\section{Safety}

In Part I, 16 AEs were reported in 9 subjects $(56.3 \%$, 9/ 16). All AEs were of grade 1. Of these, 14 AEs were related to the study drug. There was no significant trend between dose level and incidence of AEs. One subject discontinued Part I because of increased uric acid levels. In Part II, 24 AEs occurred in 9 subjects $(25 \%, 9 / 36)$. The frequency of AE occurrence was similar between the test group and the reference group (11 vs 13). Of those, 9 subjects reported 21 drug-related AEs (50\%, 8/

A

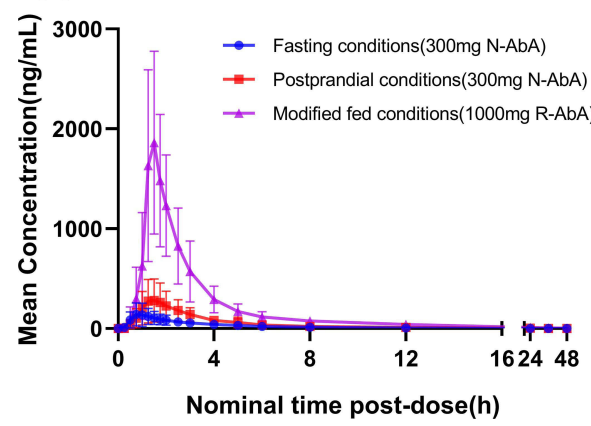

16). One subject terminated the study due to elevated blood triglyceride levels. In Part III, 28 AEs occurred in 12 subjects $(50 \%, 12 / 24)$, of which 19 AEs were related to the study drug. One subject terminated the study because of elevated levels of blood bilirubin. In all three trials, no severe AEs or AEs that caused death were reported.

The most frequent treatment-related AEs were hemobilirubin and hypertriglyceridemia. The incidence of elevated hemobilirubin and hypertriglyceridemia among patients treated with $\mathrm{N}-\mathrm{AbA}$ and $\mathrm{R}-\mathrm{AbA}$ did not differ. Other AEs included urinary tract infection, cough, hypertension, arrhythmia, and diarrhea. The details are shown in Table 5. All treatment-related AEs in this study are reported in the specification for ZYTIGA $^{\circledR}$.

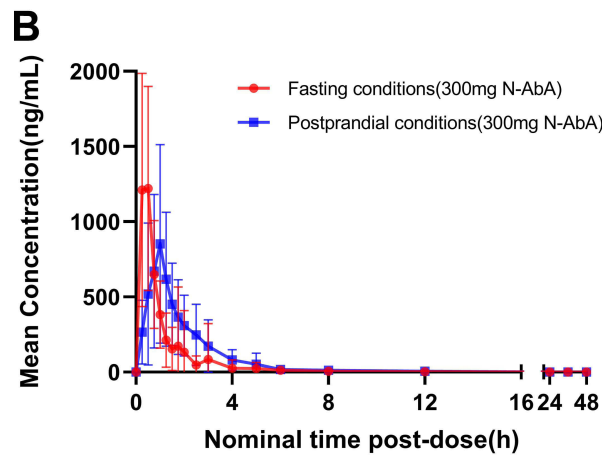

Figure 4 Mean plasma concentration-time plot of Abiraterone (A) and SNAC (B) under fasting conditions, postprandial conditions and modified fed conditions. 
Table 4 Mean Pharmacokinetic Parameters of Abiraterone and SNAC

\begin{tabular}{|c|c|c|c|c|}
\hline \multirow[t]{2}{*}{ PK Parameters } & \multicolumn{3}{|c|}{ Geometric Mean (Abiraterone) } & \multirow[t]{2}{*}{$90 \% \mathrm{Cl}$} \\
\hline & $\begin{array}{l}\text { Modified Fed Condition } \\
\text { (1000 mg R-ABA) } \\
(n=23)\end{array}$ & $\begin{array}{c}\text { Postprandial } \\
\text { Conditions } \\
(300 \mathrm{mg} \mathrm{N}-\mathrm{AbA}) \\
(\mathrm{n}=24)\end{array}$ & Ratio (\%) & \\
\hline $\mathrm{C}_{\max }(\mathrm{ng} / \mathrm{mL})$ & 2000.25 & 339.77 & 588.71 & $458.06 \% \sim 756.63 \%$ \\
\hline $\mathrm{AUC}_{0-\mathrm{t}}\left(\mathrm{ng} \mathrm{g}^{*} / \mathrm{mL}\right)$ & 4037.82 & 938.97 & 430.03 & $368.90 \% \sim 501.29 \%$ \\
\hline $\mathrm{AUC}_{0-\infty}(\mathrm{ng} * \mathrm{~h} / \mathrm{mL})$ & 4079.87 & 951.78 & 428.66 & $368.09 \% \sim 499.19 \%$ \\
\hline \multirow[t]{2}{*}{ PK Parameters } & \multicolumn{3}{|c|}{ Geometric Mean (SNAC) } & \multirow[t]{2}{*}{$90 \% \mathrm{Cl}$} \\
\hline & $\begin{array}{l}\text { Postprandial Conditions } \\
(300 \mathrm{mg} \text { N-ABA) }(n=24)\end{array}$ & $\begin{array}{l}\text { Fasting Conditions } \\
\text { (300 mg N-AbA) } \\
(n=23)\end{array}$ & Ratio (\%) & \\
\hline $\mathrm{C}_{\max }(\mathrm{ng} / \mathrm{mL})$ & 971.82 & 1356.56 & 71.64 & $52.71 \% \sim 97.36 \%$ \\
\hline$A \cup C_{0-t}(\mathrm{ng} \cdot \mathrm{h} / \mathrm{mL})$ & 1523.99 & 1207.92 & 126.17 & $114.72 \% \sim 138.75 \%$ \\
\hline $\mathrm{AUC}_{0-\infty}(\mathrm{ng} \cdot \mathrm{h} / \mathrm{mL})$ & 1531.14 & 1215.99 & 125.92 & $114.57 \% \sim 138.39 \%$ \\
\hline
\end{tabular}

\section{Discussion}

The main results of Part I showed linear pharmacokinetic characteristics of abiraterone and SNAC in the range of 75$450 \mathrm{mg}$ after a single oral administration of N-AbA on an empty stomach. N-AbA was safe and well tolerated during the trial. In the $300 \mathrm{mg}$ cohort, the $\mathrm{C}_{\max }$ and $\mathrm{AUC}_{0-\infty}$ of abiraterone were $81.4 \mathrm{ng} / \mathrm{mL}$ and $250.27 \mathrm{ng} \cdot \mathrm{h} / \mathrm{mL}$, respectively, which were similar to the values reported in previous studies on R-AbA. ${ }^{13}$ Based on these data, we further evaluated and compared the pharmacokinetics of $300 \mathrm{mg} \mathrm{N}-\mathrm{AbA}$ and 1000 mg R-AbA.

The results of Part II showed that under fasting condition, the test/reference geometric mean ratios are all within the range of $80 \%$ to $125 \%$ indicating that the exposure of $\mathrm{N}-\mathrm{AbA} 300 \mathrm{mg}$ was bioequivalent with that of R-AbA $1000 \mathrm{mg}$, and the intra-individual variation in $\mathrm{AUC}_{0-\mathrm{t}}$ and $\mathrm{AUC}_{0-\infty}$ for N-AbA was lower than that for R-AbA. As the CYP17 inhibitor, abiraterone acetate had some side effects such as fluid retention, hypertension, and hypokalemia. Lowdose prednisone decreases steroid build-up upstream of CYP17 and prevents mineralocorticoid excess. ${ }^{14}$ In 2012, AbA plus prednisone was approved by FDA for the treatment of patients with mCRPC. European Association of Urology guidelines on the treatment of CRPC mention this combination as one of the first-line treatments for CRPC. ${ }^{15}$ Thus, in Part II, we also studied whether SNAC would affect prednisone pharmacokinetics. The pharmacokinetic parameters of prednisone and prednisolone were similar after the combined use of N-AbA or R-AbA, indicating that SNAC had no effect on the pharmacokinetics of prednisone and prednisolone.

The specifications for ZYTIGA ${ }^{\circledR}$ state that the tablets must be taken on an empty stomach and should not be taken at least 2 $\mathrm{h}$ before and at least $1 \mathrm{~h}$ after administration because food effects can result in fluctuations in drug exposure. Therefore, in Part III, we set up a modified fed group based on these two time nodes. The results showed that after oral administration of the test drug after a high-fat meal, the $\mathrm{C}_{\max }$ of abiraterone increased only by about 2.2 times, and the $\mathrm{AUC}_{0-\infty}$ increased by about 2 times, indicating that $\mathrm{N}-\mathrm{AbA}$ has a significantly lower food effect than R-AbA. Thus, even if patients do not follow regular diet management before and after taking the drug, drug exposure will not be drastically altered, which is an important safety advantage.

YONSA $^{\circledR}$, the improved version of R-AbA, was approved for the treatment of patients with mCRPC in 2018. The proprietary YONSA ${ }^{\circledR}$ formulation using SoluMatrix Fine Particle Technology ${ }^{\mathrm{TM}}$ allows for the same systemic exposure to be achieved with $500 \mathrm{mg}$ relative to the recommended dose of R-AbA 1000 mg. ${ }^{16}$ The $\mathrm{C}_{\max }$ of abiraterone was approximately 6.5-fold higher, and the $\mathrm{AUC}_{0-\infty}$ was 4.4-fold higher when a single dose of YONSA $500 \mathrm{mg}$ was administered with a high-fat meal (56-60\% fat, 900-1000 calories) than when administered after overnight fasting in healthy subjects. ${ }^{17}$ Nanocrystalline technology and the addition of SNAC further improve the bioavailability of N-AbA and reduce the impact of food. 
Table 5 Summary of Treatment-Related AEs Occurred in the Study

\begin{tabular}{|c|c|c|c|c|}
\hline \multirow[t]{2}{*}{ AEs (No. of AEs, No. (\%) of Subjects) } & \multicolumn{4}{|c|}{ Part I $(n=16)$} \\
\hline & $\begin{array}{l}75 \mathrm{mg} \\
(\mathrm{n}=16)\end{array}$ & $\begin{array}{l}150 \mathrm{mg} \\
(n=15)\end{array}$ & $\begin{array}{l}300 \mathrm{mg} \\
(\mathrm{n}=\mid 5)\end{array}$ & $\begin{array}{l}450 \mathrm{mg} \\
(n=15)\end{array}$ \\
\hline Laboratory & $3(3,18.8)$ & $6(4,26.7)$ & $6(6,40.0)$ & $I(I, 6.7)$ \\
\hline Triglyceride increased & $\mathrm{I}(\mathrm{I}, 6.3)$ & $\mathrm{I}(\mathrm{I}, 6.7)$ & $3(3,20.0)$ & $\mathrm{I}(\mathrm{I}, 6.7)$ \\
\hline Bacteria & $\mathrm{I}(\mathrm{I}, 6.3)$ & $I(I, 6.7)$ & $0(0,0)$ & $0(0,0)$ \\
\hline Hemobilirubin increased & $0(0,0)$ & $2(2,13.3)$ & $0(0,0)$ & $0(0,0)$ \\
\hline Urokinase protein & $0(0,0)$ & $I(I, 6.7)$ & $0(0,0)$ & $0(0,0)$ \\
\hline Urine erythrocyte & $0(0,0)$ & $\mathrm{I}(\mathrm{I}, 6.7)$ & $0(0,0)$ & $0(0,0)$ \\
\hline Hematuresis & $0(0,0)$ & $0(0,0)$ & $I(I, 6.7)$ & $0(0,0)$ \\
\hline TBA increased & $0(0,0)$ & $0(0,0)$ & $\mathrm{I}(\mathrm{I}, 6.7)$ & $0(0,0)$ \\
\hline \multirow[t]{2}{*}{ AEs (No. of AEs, No. (\%) of Subjects) } & \multicolumn{4}{|c|}{ Part II $(n=36)$} \\
\hline & \multicolumn{2}{|l|}{$T *(n=36)$} & \multicolumn{2}{|c|}{$R^{*}(n=35)$} \\
\hline Laboratory & \multicolumn{2}{|l|}{$10(7,19.4)$} & \multicolumn{2}{|c|}{$13(6,17.1)$} \\
\hline Triglyceride increased & \multicolumn{2}{|l|}{$5(4,11.1)$} & \multicolumn{2}{|c|}{$6(3,8.6)$} \\
\hline Bacteria & \multicolumn{2}{|l|}{$0(0,0)$} & \multicolumn{2}{|c|}{$0(0,0)$} \\
\hline Hemobilirubin increased & \multicolumn{2}{|l|}{$3(2,5.6)$} & \multicolumn{2}{|c|}{$2(1,2.9)$} \\
\hline DBil increased & \multicolumn{2}{|l|}{$0(0,0)$} & \multicolumn{2}{|c|}{$I(I, 2.9)$} \\
\hline Urine leukocyte & \multicolumn{2}{|l|}{$0(0,0)$} & \multicolumn{2}{|c|}{$\mathrm{I}(\mathrm{I}, 2.9)$} \\
\hline AST increased & \multicolumn{2}{|l|}{$\mathrm{I}(\mathrm{I}, 2.8)$} & \multicolumn{2}{|c|}{$0(0,0)$} \\
\hline Gastrointestinal & \multicolumn{2}{|l|}{$\mathrm{I}(\mathrm{I}, 2.8)$} & \multicolumn{2}{|c|}{$0(0,0)$} \\
\hline Ventosity & \multicolumn{2}{|l|}{$\mathrm{I}(\mathrm{I}, 2.8)$} & \multicolumn{2}{|c|}{$0(0,0)$} \\
\hline \multirow[t]{2}{*}{ AEs (No. of AEs, No. (\%) of subjects) } & \multicolumn{4}{|c|}{ Part III $(n=24)$} \\
\hline & $\begin{array}{l}\text { Fasting Conditions } \\
\qquad\left(\mathrm{T}^{\#}, \mathrm{n}=\mathbf{2 3}\right)\end{array}$ & $\begin{array}{l}\text { Postprar } \\
\text { Conditi } \\
\left(T^{\#}, n=\right.\end{array}$ & M & $\begin{array}{l}\text { ed Fed Conditions } \\
\left(R^{\#}, n=23\right)\end{array}$ \\
\hline Laboratory & $9(7,30.4)$ & $9(7,29$ & & $5(3,13.0)$ \\
\hline Triglyceride increased & $4(4,17.4)$ & $4(4,16$ & & $\mathrm{I}(\mathrm{I}, 4.3)$ \\
\hline Hemobilirubin increased & $0(0,0)$ & $\mathrm{I}(\mathrm{I}, 4$. & & $0(0,0)$ \\
\hline TBA increased & $\mathrm{I}(\mathrm{I}, 4.3)$ & $0(0,0$ & & $0(0,0)$ \\
\hline WBC increased & $0(0,0)$ & $\mathrm{I}(\mathrm{I}, 4$. & & $0(0,0)$ \\
\hline Liver enzymes increased & $0(0,0)$ & $0(0,0$ & & $I(I, 4.3)$ \\
\hline Neutrophil count increased & $0(0,0)$ & $\mathrm{I}(\mathrm{I}, 4$. & & $0(0,0)$ \\
\hline Gastrointestinal & $0(0,0.0 \%)$ & $0(0,0$ & & $4(2,8.3)$ \\
\hline Stomachache & $0(0,0.0 \%)$ & $0(0,0$ & & $2(2,8.3)$ \\
\hline Diarrhea & $0(0,0.0 \%)$ & $0(0,0$ & & $2(2,8.3)$ \\
\hline Respiratory & $0(0,0.0 \%)$ & $0(0,0$ & & $2(2,8.3)$ \\
\hline Cough & $0(0,0.0 \%)$ & $0(0,0$ & & $2(2,8.3)$ \\
\hline
\end{tabular}

Notes: T*: 300mg N-AbA+5mg prednisone; R*: 1000mg R-AbA+5mg prednisone. T : 300mg N-AbA; R*: 1000mg R-AbA.

Abbreviations: AE, adverse event; TBA, total bile acid; WBC, white blood cells; AST, aspartate aminotransferase.

SNAC is a new type of absorption enhancer originally developed by Emisphere Technology Inc. Despite it not being listed in the FDA excipient database at present, SNAC is widely used in improving the oral absorption of different types of drugs, including proteins and macromolecules, such as insulin, calcitonin, and heparin. ${ }^{18,19}$ SNAC has been reported to enhance the oral bioavailability of the long-acting GLP-1 analog semaglutide, which is used to treat type 2 diabetes and was approved by the FDA on September 20, 2019. ${ }^{20,21}$ A vitamin B12 product that exhibits enhanced oral absorption due to SNAC is already marketed. ${ }^{22}$ This study confirms that the use of SNAC not only improves the bioavailability of abiraterone but also greatly reduces the effect of food on the absorption of 
abiraterone. SNAC may be used to enhance the oral bioavailability of several other drugs.

\section{Conclusion}

$\mathrm{N}-\mathrm{AbA}$ and the excipient SNAC showed linear pharmacokinetic characteristics within the dose range of $75 \mathrm{mg}$ $450 \mathrm{mg}$. A single $300 \mathrm{mg}$ dose of N-AbA was bioequivalent to $1000 \mathrm{mg}$ of $\mathrm{R}-\mathrm{AbA}$ in healthy subjects under fasting conditions. Meanwhile, no pharmacokinetic interactions were observed between SNAC and prednisone after combined administration of prednisone. N-AbA shows lower intra-individual variation and food effects than $\mathrm{R}-\mathrm{AbA}$.

\section{Data Sharing Statement}

The original contributions presented in the study are included in the article, and further inquiries can be directed to the corresponding author.

\section{Acknowledgments}

This study was funded by Jiangsu Hengrui Medicine Co., Ltd. and the Key Research and Development Project of Hunan Province (2020SK2010) as well as the Hunan Provincial Natural Science Foundation of China (No. 2020JJ5852). Zeying Feng and Yaxin Liu are cofirst authors for this study.

\section{Disclosure}

YH was employed by Jiangsu Hengrui Medicine Co., Ltd. The authors report no other conflicts of interest in this work.

\section{References}

1. Cancer.Net. Prostate cancer: statistics; 2021. Available from: https:// www.cancer.net/cancer-types/prostate-cancer/statistics. Accessed September 15, 2021.

2. Teoh JYC, Hirai HW, Ho JMW, Chan FCH, Tsoi KKF, Ng CF. Global incidence of prostate cancer in developing and developed countries with changing age structures. PLoS One. 2019;14(10):e0221775. doi:10.1371/journal.pone. 0221775

3. Ryan CJ, Smith MR, Fong L, et al. Phase I clinical trial of the CYP17 inhibitor Abiraterone acetate demonstrating clinical activity in patients with castration-resistant prostate cancer who received prior ketoconazole therapy. J Clin Oncol. 2010;28(9):1481-1488. doi:10.1200/ jco.2009.24.1281

4. Ryan CJ, Smith MR, Fizazi K, et al. Abiraterone acetate plus prednisone versus placebo plus prednisone in chemotherapy-naive men with metastatic castration-resistant prostate cancer (COU-AA-302): final overall survival analysis of a randomised, double-blind, placebo-controlled Phase 3 study. Lancet Oncol. 2015;16 (2):152-160. doi:10.1016/s1470-2045(14)71205-7
5. Caffo O, Veccia A, Kinspergher S, Maines F. Abiraterone acetate and its use in the treatment of metastatic prostate cancer: a review. Fut Oncol. 2018;14(5):431-442. doi:10.2217/fon-20170430

6. Boleslavská T, Rychecký O, Krov M, et al. Bioavailability enhancement and food effect elimination of Abiraterone acetate by encapsulation in surfactant-enriched oil marbles. AAPS J. 2020;22(6):122. doi:10.1208/s12248-020-00505-5

7. FDA Center for Drug Evaluation and Research (CDER). Clinical pharmacology and biopharmaceutics review(s): application number:2023790rig1s000. Available from: http://www.accessdata. fda.gov/drugsatfda_docs/nda/2011/202379Orig1s000ClinPharmR. pdf. Accessed September 15, 2021.

8. Schultz HB, Meola TR, Thomas N, Prestidge CA. Oral formulation strategies to improve the bioavailability and mitigate the food effect of Abiraterone acetate. Int J Pharm. 2020;577:119069. doi:10.1016/j. ijpharm.2020.119069

9. Buckley ST, Bækdal TA, Vegge A, et al. Transcellular stomach absorption of a derivatized glucagon-like peptide-1 receptor agonist. Sci Transl Med. 2018;10(467). doi:10.1126/scitranslmed. aar7047

10. Bucheit JD, Pamulapati LG, Carter N, Malloy K, Dixon DL, Sisson EM. Oral semaglutide: a review of the first oral glucagon-like peptide 1 receptor agonist. Diabetes Technol Ther. 2020;22(1):10-18. doi:10.1089/dia.2019.0185

11. Baekdal TA, Donsmark M, Hartoft-Nielsen ML, Søndergaard FL, Connor A. Relationship between oral semaglutide tablet erosion and pharmacokinetics: a pharmacoscintigraphic study. Clin Pharmacol Drug Dev. 2021;10(5):453-462. doi:10.1002/cpdd.938

12. Li Y, Yang D, Zhu C. Impact of sodium N-[8-(2-Hydroxybenzoyl) amino]-caprylate on intestinal permeability for notoginsenoside R1 and salvianolic acids in Caco-2 cells transport and rat pharmacokinetics. Molecules. 2018;23(11):2990. doi:10.3390/ molecules 23112990

13. Wang C, Hu C, Gao D, et al. Pharmacokinetics and bioequivalence of generic and branded Abiraterone acetate tablet: a single-dose, open-label, and replicate designed study in healthy Chinese male volunteers. Cancer Chemother Pharmacol. 2019;83(3):509-517. doi:10.1007/s00280-018-3754-x

14. Crawford ED, Shore ND, Petrylak DP, et al. Abiraterone acetate and prednisone in chemotherapy-naïve prostate cancer patients: rationale, evidence and clinical utility. Ther Adv Med Oncol. 2017;9 (5):319-333. doi:10.1177/1758834017698644

15. Heidenreich A, Bastian PJ, Bellmunt $\mathrm{J}$, et al. EAU guidelines on prostate cancer. Part II: treatment of advanced, relapsing, and castration-resistant prostate cancer. Eur Urol. 2014;65(2):467-479. doi:10.1016/j.eururo.2013.11.002

16. Goldwater R, Hussaini A, Bosch B, Nemeth P. Comparison of a novel formulation of Abiraterone acetate vs. the originator formulation in healthy male subjects: two randomized, open-label, crossover studies. Clin Pharmacokinet. 2017;56(7):803-813. doi:10.1007/ s40262-017-0536-2

17. FDA Center for Drug Evaluation and Research (CDER). Clinical pharmacology and biopharmaceutics review(s): application number:2103080rig1s000. Avaliable from: https://www.accessdata. fda.gov/drugsatfda_docs/nda/2018/210308Orig1s000ClinPharmR. pdf. Accessed September 15, 2021.

18. Bandeira L, Lewiecki EM, Bilezikian JP. Pharmacodynamics and pharmacokinetics of oral salmon calcitonin in the treatment of osteoporosis. Expert Opin Drug Metab Toxicol. 2016;12 (6):681-689. doi:10.1080/17425255.2016.1175436

19. Welt FG, Woods TC, Edelman ER. Oral heparin prevents neointimal hyperplasia after arterial injury: inhibitory potential depends on type of vascular injury. Circulation. 2001;104(25):3121-3124. doi: $10.1161 /$ hc5001.100837 
20. Andersen A, Knop FK, Vilsbøll T. A pharmacological and clinical overview of oral semaglutide for the treatment of type 2 diabetes. Drugs. 2021;81(9):1003-1030. doi:10.1007/s40265-021-01499-w

21. Newsome PN, Buchholtz K, Cusi K, et al. A placebo-controlled trial of subcutaneous semaglutide in nonalcoholic steatohepatitis. $N$ Engl $J$ Med. 2021;384(12):1113-1124. doi:10.1056/NEJMoa2028395
22. Castelli MC, Wong DF, Friedman K, Riley MG. Pharmacokinetics of oral cyanocobalamin formulated with sodium $\mathrm{N}$-[8-(2-hydroxybenzoyl) amino]caprylate (SNAC): an open-label, randomized, single-dose, parallel-group study in healthy male subjects. Clin Ther. 2011;33 (7):934-945. doi:10.1016/j.clinthera.2011.05.088

\section{Publish your work in this journal}

Drug Design, Development and Therapy is an international, peerreviewed open-access journal that spans the spectrum of drug design and development through to clinical applications. Clinical outcomes, patient safety, and programs for the development and effective, safe, and sustained use of medicines are a feature of the journal, which has also been accepted for indexing on PubMed Central. The manuscript management system is completely online and includes a very quick and fair peer-review system, which is all easy to use. Visit http://www. dovepress.com/testimonials.php to read real quotes from published authors. 